\title{
BUROCRACIA EDUCATIVA, TRABAJO DOCENTE Y GÉNERO: SUPERVISORAS QUE CONDUCEN "PONIENDO EL CUERPO"
}

\author{
Graciela Morgade*
}

\begin{abstract}
RESUMEN: Existe en la actualidad un importante corpus de investigaciones que indagan cómo en el nivel primario de la educación formal las significaciones de género que son hegemónicas en la vida escolar y en la vida social en su conjunto se articulan con las definiciones del trabajo docente de maestras y maestros. El presente artículo se nutre de una tesis doctoral dirigida a analizar las dinámicas de género en la construcción del liderazgo que realizan las maestras en cargos directivos a nivel de la escuela y del "distrito" escolar. ${ }^{1}$ La hipótesis central que se despliega en la tesis es que las tensiones propias del encuentro entre, por una parte, la normativa y las políticas del sistema educativo, y, por otra parte, los procesos subjetivos de las prácticas docentes de conducción de la dirección y la supervisión se articulan también con las significaciones de género tradicionales acerca de lo femenino y lo masculino.
\end{abstract}

Palabras clave: Trabajo docente. Género. América Latina.

\section{EDUCATIONAL BUREAUCRACY, TEACHER'S WORK AND GENDER: FEMALE SUPERVISORS PHYSICALLY INVOLVED IN MANAGEMENT}

ABSTRACT: There currently exists an important corpus of research wondering how, in the primary level of formal education, the meanings of gender that are hegemonic in school life and in life social as a whole are articulated with the definitions of the work of male and female teachers. The present paper draws on a $\mathrm{PhD}$ thesis, recently defended at the University of Buenos Aires, that analyzed the dynamics of gender in the building of leadership carried on by female teachers occupying management position at school and school "district" levels. The main hypothesis developed in this thesis is that the

Profesora e investigadora en el Departamento de Ciencias de la Educación de la Facultad de Filosofía y Letras de la Universidad de Buenos Aires.E-mail: gmorgade@filo.uba.ar 
tensions characteristic of the encounter between normativeness and the educational system policies, on the one hand, and the subjective processes of the teaching practices of board management and supervision are also articulated with the traditional meanings of gender views of male and female.

Key words: Teaching work. Gender. Latin America.

$\mathscr{E}$ 1 trabajo focalizará la indagación del problema en el caso de mujeres a cargo de la "supervisión escolar". Si bien desde el enfoque de la construcción de la subjetividad social que sostenemos en nuestra investigación, discutimos la hipótesis de que exista un estilo "femenino" o "masculino" esencial, también entendemos que la reiteración de las prácticas que los sujetos deben realizar para satisfacer las expectativas de otros y otras frente a su labor tiene un residuo simbólico que puede llegar a reforzar estructuras de segregación y de subordinación de género. Sostendremos entonces que, como alternativas a las versiones burocráticas, familiaristas o vocacionistas-altruistas, existen formas de conducción femeninas que, con un trabajo intenso (físico y emocional) para legitimar su ejercicio, y con una fuente potente de legitimidad de su poder se fundamenta en el cuidado ${ }^{2}$ y la atención infantiles como inherentes a todo proceso de enseñanza, llegan a conducir definiendo a la enseñanza y el proyecto pedagógico escolar como la centralidad del trabajo escolar.

Maestras, significaciones de género y construcción social del "cuerpo docente"

La construcción identitaria de un sujeto es un proceso que va deparando configuraciones relativamente inestables durante toda la vida. ${ }^{3}$ No se realiza en un infinito de posibilidades, sino en diferentes ámbitos en los cuales la clase social de pertenencia, la nacionalidad o etnia, la edad, las relaciones de género etc., en tanto regímenes de poder, proveen un repertorio limitado de opciones traducidas, en general, en un conjunto con frecuencia contradictorio ${ }^{4}$ de expectativas mediante las que diferentes figuras de autoridad disputan el disciplinamiento subjetivo.

Entendemos también que la producción de "una maestra" o de "un maestro" es un proceso permanente. La experiencia en las instituciones de 
Burocracia educativa, trabajo docente y género...

formación inicial específica o en la actualización profesional continua se complementa con la producida en otros ámbitos: por una parte, la propia historia en la vida educativa y escolar; por otra, y de particular potencia, "en servicio", a través del trabajo en la escuela. Desde esta perspectiva, más que "ser maestra" estamos frente al proceso constante de "devenir maestra", proceso que comienza mucho antes de tener un título ${ }^{5}$ o conseguir un puesto y puede separarse sólo analíticamente de la socialización infantil, la formación en una institución específica o la trayectoria profesional en diversos ámbitos.

$\mathrm{La}$ "formación docente" entonces se va produciendo mediante sucesivas construcciones que combinan elementos aportados por diferentes campos de experiencia ${ }^{6}$ particular e histórica.

Entre los discursos sociales en los que la subjetividad docente se construye, el dispositivo social de control que históricamente ha determinado a "lo femenino" en contraposición a "lo masculino" - es decir, el sistema de sexo-género del mundo occidental ${ }^{7}$ - constituye uno de los más poderosos, en particular en el nivel primario.

Desde sus inicios como sistema a fines del siglo XIX, en el marco del proyecto de construir una nación civilizada y moderna, incorporando a las masas de inmigrantes y de nativos/as a un ethos compartido, el nivel primario argentino fue un espacio de trabajo para mujeres; en particular en el aula y también, aunque no en tan alta proporción como veremos, en la dirección de las escuelas. Una de las iniciativas constitutivas de esta política fue la creación de las Escuelas Normales para la formación docente y el estímulo a las niñas y sus familias para estudiar el magisterio (Morgade, 1992, 1997): al igual que en otros países latinoamericanos (Cortina y San Román, 2006) se entendía que la enseñanza era un trabajo "apropiado para su sexo" ya que las mujeres venían educando en el hogar y sería "natural" para ellas seguir haciéndolo en la escuela. Por otra parte, su carácter dependiente desde el punto de vista económico y las escasas opciones alternativas para emplearse hacían de las mujeres una inversión estatal de rédito seguro.

La apelación a las jóvenes tuvo una gran aceptación en la sociedad civil y, en particular, entre las familias. En una sociedad dividida en clases netamente diferenciadas (las familias tradicionales del período colonial, terratenientes y ganaderas por una parte, y el campesinado y la servidumbre urbana por el otro), algunos grupos sociales de 
inmigrantes comenzaban a desarrollar pequeños comercios e industrias o empresas de poca envergadura y a disputar una mayor participación en la política gubernamental. Para estos sectores, la posibilidad de educar a las hijas y mejorar su posición en el mercado matrimonial hizo de la Escuela Normal una gran oportunidad de promoción social.

La "madre educadora por vocación" constituyó entonces un nudo de sentido de fuerte adhesión social e institucional. Hasta tal punto que, así como sólo en términos teóricos, es posible distinguir los diferentes ámbitos en que se producen los procesos de "formación docente", también es producto de un esfuerzo analítico establecer la distinción entre la "feminización", en términos de presencia cuantitativa de mujeres en el trabajo docente y la "feminización" de las maestras como sujetos (o, según algunas investigadoras en la tradición brasileña, ${ }^{8}$ "feminilización" en tanto construcción subjetiva de una femineidad). Tal es, desde nuestra perspectiva, la potencia de su interrelación.

Esta hipótesis no desconoce la presencia masculina en el magisterio, minoritaria pero siempre perceptible. Hemos estudiado con anterioridad también (Morgade, 1992) las diferencias entre los modos de inserción y de ejercicio en el trabajo docente de maestras y maestros, evidenciando también que en la escuela no desarrollan su tarea de modos similares, construyendo diferentes vínculos con alumnos/as, autoridades, colegas, familias y, en general, con los requerimientos burocráticos, tendiendo los maestros varones a ser relevados de ciertas tareas administrativas, a gozaren de cierto prejuicio "positivo" frente a su llegada y, en general, a ser "cuidados" como un recurso escaso.

Sostenemos entonces que, en tanto relaciones de poder, las relaciones de género derivadas de la división sexual del trabajo propias del capitalismo industrial y la era de la revolución burguesa han marcado y marcan la subjetividad social docente. Pero dado que, antes que poseer una "esencia femenina", los sujetos "se hacen femeninos" (o "masculinos”) al interactuar con los significados hegemónicos, también se producen discontinuidades, rupturas, cambios y nuevas configuraciones ${ }^{9}$ vinculados con los diferentes ámbitos de experiencia y también con los procesos sociales más amplios ligados con lógicas económicas y políticas, así como en los procesos familiares e individuales.

La escuela fue tanto un espacio de construcción de posibilidades de desarrollo profesional remunerado como una instancia de reforzamiento 
de los discursos de género en vías de consolidación en la pequeña burguesía, configurando una definición de la tarea docente estrechamente vinculada con el imaginario de la entrega, la afectividad, la paciencia, el cuidado etc. propias de ese sector social, al tiempo que como los mandatos del positivismo requerían más bien una formación "científica" se constituían en subordinadas en la lucha por la construcción del conocimiento. Pero también fue un escenario público, fuera del hogar, vaso comunicante con lecturas, personas y contextos variados que también integraron la "formación docente". Así, la escuela ha sido sede de conflictos y negociaciones de género entre grupos y entre personas en términos del poder estatal, doméstico y parental.

En la actualidad, las mujeres representan en la Argentina el $92,3 \%$ de las/os maestras/os de grado. Los significados "vocacionistas" fundacionales fueron cambiando de intensidad a lo largo del siglo, pero resultan persistentes aún en la actualidad a pesar del embate tecnicista y modernizante de la década del 60, y del consenso de la categoría "trabajador de la educación" sostenida por la organización gremial y ampliamente difundida en el sector desde los 70, con fuertes críticas a la ideología del apostolado, a los bajos salarios y a la sobrecarga de la doble o triple jornada laboral docente (con su trabajo invisible) que lleva al malestar y stress persistentes.

Estas contradicciones conviven también con las tendencias a la "profesionalización" del trabajo por parte del discurso oficial de fines de los 80 y de los 90 - en paralelo a la intensifición y precarización del trabajo (Feldfeber y Oliveira, 2006) -, y recientemente, con la tendencia a la profundización del papel asistencial de la docencia en función de la pauperización y dualización generadas por la transformación neoliberal del país y, en particular, de la crisis que en el año 2001 golpeó a la Argentina: el fuerte desempleo (llegó al 22\%), el crecimiento de la pobreza y la indigencia, el achicamento del Estado y la reducción de las políticas sociales colocaron a la escuela en un lugar de asistencia y contención que tendió a reforzar, nuevamente, los aspectos más "tradicionales" el trabajo docente.

Ahora bien, a fines del siglo XIX, mientras a través de los contenidos "femeninos" de la cultura familiar se atraía a las mujeres a las escuelas para ser maestras, se sostenía que "enseñar no es dirigir": las mujeres llegaban a ser directoras solo cuando no había un maestro varón 
disponible en la escuela y quedaban totalmente excluidas de la conducción intermedia del sistema (la Inspección Escolar), más ligada a lealtades políticas que estrictamente técnicas.

Si, siguiendo a Epstein (1993, p. 49), las relaciones de poder resultan de un sedimento de su ejercicio sostenido por parte de quien lo detenta y se legitiman en un orden que es anterior a la consolidación de esas relaciones, en un sistema estatal en construcción, rudimentario y precario, en tanto "portadores" concentrados de las significaciones de género correspondientes a lo masculino, los hombres tendían a "sumar" legitimidad a los cargos que ocupaban, resultando el poder formal reforzado por la "autoridad" (en tanto poder legítimo) masculina y, también, en el sentido inverso (que quien ocupaba el cargo de inspección resultaba más "autorizado" por el estado educador).

Durante años, quienes pasaron a desarrollar esas funciones llegaron desde las aulas sin una preparación específica ${ }^{10}$ sino más bien como corolario de su experiencia docente y vital, y, más bien, de sus contactos políticos. La progresiva institucionalización de concursos derivó en que las mujeres ocuparan los cargos a partir de su formación y su experiencia. Pero la dinámica cultural de las escuelas tendió a conservar rasgos de género diferenciales. Como veremos, la "autoridad" parece mantener aún una connotación "masculina", observándose con frecuencia mejor predisposición de la comunidad educativa e inclusive los equipos docentes frente al ejercicio de los roles directivos por parte de varones.

En la actualidad, en la ciudad de Buenos Aires, las mujeres representan el $87 \%$ de las/os directoras/es de escuela. Sin embargo, son el $33 \%$ en la supervisión escolar. Sostendremos e intentaremos mostrar que en la dirección y, mucho más en la supervisión, las significaciones de género inciden y tensionan los modos de construcción, legitimación y ejercicio del poder.

La "carrera docente" y la progresiva alienación de los saberes pedagógicos de las maestras

$\mathrm{Al}$ igual que en muchos países "nuevos" latinoamericanos y europeos, en la Argentina se adoptó una organización "napoleónica"11 que, a fines del siglo XIX, fue la estrategia estatal clave en el marco de las políticas tendientes a la construcción de la nación, en particular por 
Burocracia educativa, trabajo docente y género...

su territorio extenso y escasamente poblado. La conformación de una sucesión piramidal de autoridades ${ }^{12}$ en el sistema educativo respondió a esta misma lógica, implicando la aparición de nuevos sujetos y roles que podríamos denominar "supra-pedagógicos", definidos como instancias de reaseguro de la aplicación de las políticas educativas, interlocución directa de las autoridades políticas o regionales, sede de la responsabilidad patrimonial y educativa. La lógica burocrática implica una organización piramidal en que cada estamento es "responsable" (alude al control sobre su propio trabajo) y a la vez "garante" (controlando a otros) del funcionamiento a la institución. La legitimidad del poder (o sea la autoridad) emana de la jerarquía burocrática y, en última instancia, del Estado educador que concentra, hacia los/as docentes, la posibilidad de acceder al trabajo y también la de la sanción, o de expulsión (con la consecuente pérdida del empleo). La concentración burocrática en la cabeza de la pirámide del sistema educativo es funcional a la dinámica "arriba-abajo" (la dirección controla a todo el personal de la escuela, la supervisión controla a la dirección).

El supuesto central de funcionamiento es que representa una forma weberiana racional y por lo tanto, ordenada y objetiva, de manejo institucional. Sin embargo, la naturaleza racional del poder burocrático escolar es desafiada en forma cotidiana en su ejercicio, ya que las normas no son solamente aplicadas sino que son resignificadas de manera permanente. Con frecuencia, la resignificación corre por cuenta de quien la realiza y, en ocasiones, puede aplicarse en sentidos divergentes reforzando, en este sentido, el imaginario violento. ${ }^{13} \mathrm{La}$ autoridad burocrática escolar encarna la "violencia" además detentando el poder para calificar el trabajo y al/a trabajador/a de la educación. Este proceso se percibe generalmente como relacionado con la "descalificación", resultando casi imposible el seguimiento, el asesoramiento o la calificación del trabajo y diseñar proyectos comunes, consensuar y hacerse cargo o disentir con la directora o el director, el poder "en última instancia". Nuevamente, un imaginario del poder que la lógica burocrática tiende a construir como violento.

Estos dos nudos de sentido (aplicar las normas disciplinarias y, en ocasiones, de modo arbitrario a la vez que se tiene el poder de calificar al trabajo docente) se contraponen con frecuencia a la lógica pedagogica de la docencia: la escuela es también un ámbito de trabajo profesional (Anderson, 1991; Ball, 1994; Hargreaves, 1996; Batallán, 
2003 , 2007). En tanto tal, las formas de control deben también configurarse según una definición autónoma del trabajo escolar y la posibilidad del intercambio entre pares, entre "colegas". La legitimidad del poder en este discurso estaría ligada a la experiencia o el conocimiento y, aún más, cuando se reconoce que los/as subordinados/as también tienen experiencia y conocimiento.

La dirección. En la vida cotidiana de la escuela parece existir una contradicción entre la lógica de la especificidad pedagógica del trabajo docente y la lógica del trabajo burocrático funcionario que atraviesa las interacciones en las escuelas. Las lábiles redes de funcionamiento escolar parecen sostenerse en que la solidaridad primaria dentro de la escuela permita una alianza implícita o explícita para el mantenimiento del orden. La autoridad deviene entonces indispensable en su dimensión burocrática, mientras que en su dimensión pedagógica se subsana su ausencia de modo individual, dentro de cada aula, tendiendo a alienar la participación en la política institucional.

Sin embargo, las relaciones que se dan en las escuelas caracterizables con frecuencia como "semidomésticas" hacen que el imaginario del poder como imposición, como amenaza de ejercicio de la violencia, privativo de las organizaciones jerárquicas, también se conjugue con la representación de la autoridad según el patrón de la familia arcaica. Si la institución escolar debe fundamentalmente mantener el orden para funcionar "normalmente", la figura del/a director/a actuará un papel represivo; un papel similar al del "padre arcaico". Un padre frente al/a la cual los/as hijos/as no pueden sino someterse y rebelarse a la vez, al igual que en los vínculos familiares. Y al igual que en la familia, cuando se busca el reconocimiento paterno, los/as maestros/as interactúan rivalizando entre sí y desplegando resistencias y resentimientos hacia la autoridad inmediata superior (el director para los maestros, el supervisor para los directores): la autoridad, "autoritaria" en este sentido, genera una oposición solapada y permanente a la conducción. Con más frecuencia que sus colegas varones, las mujeres no funcionan como "padre"; sin embargo, pueden llegar a establecer alianzas por "congenialidad" que operan también en un sentido fragmentador entre "queridas/os" y "no queridas/os", obstaculizándose también la conducción escolar de la institución global.

Parecería que tanto las relaciones burocráticas como el patrón "familiarista" particularizado por las significaciones de género limitan 
Burocracia educativa, trabajo docente y género...

la construcción de formas de autoridad y gestión colaborativas necesarias para impulsar cambios organizacionales permanentes en la escuela en la perspectiva de la democratización social y política de la sociedad global.

Pero en otras ocasiones, la validación puede adquirir también contenidos de género cuya fuente de poder no está ya en el orden violento ni en la conservación de los significados hegemónicos de género. La crisis que la Argentina viene atravesando ha interpelado las inclinaciones de las directoras hacia el hacerse cargo de cuestiones básicas de supervivencia tales como alimentación, vestimenta, vivienda, seguridad, salud primaria etc. Justificando la aplicación de la normativa en una excesiva valoración de estas funciones el poder se legitima, nuevamente, en el sentido más tradicional de una versión "vocacionista-altruista". Un matiz de "justicia social" puede llegar a politizar estas preocupaciones y a legitimar al trabajo de la escuela como compromiso con las condiciones mínimas de existencia necesarias para aprender.

Tanto en un sentido descriptivo como en su dimensión política propositiva, las mujeres, en sus intentos fallidos como en sus intentos emancipatorios y profesionalizantes, deben ejercer su poder, en todos los casos, "poniendo el cuerpo". Sin embargo, parecería que los modos femeninos alcanzan su despliegue más igualitario (en forma de una igualdad compleja ${ }^{14}$ ) y justos apelando fundamentalmente a los contenidos profesionales colegiales.

La supervisión. Desde la perspectiva burocrática de "carrera", una primera característica para todos y todas es que las oportunidades para llegar a la supervisión son reducidas: las aproximadamente 439 escuelas primarias que tienen director/a, vicedirector/a y secretario/a (algunas con más de una vicedirección o secretaría) están organizadas en 21 distritos, cada uno de los cuales cuenta solamente con un/a supervisor/a escolar y un/a supervisor/a adjunto/a.

La composición cuantitativa muestra que las mujeres "hacen carrera" dentro de la escuela (hasta ser directoras), pero su creciente participación en los cargos de conducción cambia de tendencia cuando "salen" de los muros escolares. En este sentido, aún están (auto) excluidas del poder concentrado del Estado.

Dos cuestiones de características políticas parecen el marco de esta configuración. Por una parte, en los 80 se reflotó una antigua norma que establecía el "tres por uno" en la cobertura de cargos: cada tres 
mujeres que accedían a un cargo lo hacía un varón, independientemente de su puntaje; una suerte de "acción positiva" para atraer a los varones al magisterio (del cual no estaban excluidos formalmente, solo que no les interesaba ejercerlo). Esta norma favoreció a muchos varones en la obtención de su primer cargo titular con a edad muy temprana y, en este sentido, abonó también una carrera más acelerada. Por otra parte, si bien la ciudad de Buenos Aires no adhirió activamente a la reforma educativa de los 90, ésta configuró un momento crítico desde el punto de vista político, para el gobierno del Estado y para los gremios docentes: los modelos institucionales alentados por las políticas internacionales en educación sumadas a fuertes cuestionamiento oficiales a las/os docentes llevaron a una fuerte tensión en el sector que tendió a requerir, más que en las décadas anteriores, de un refuerzo del "orden" frente a la amenaza del caos.

La autoridad "masculina" de los supervisores varones sería entonces, en cierta medida, anterior y complementaria a la "funcionaria" otorgada por el cargo. En términos weberianos laxos diríamos que el liderazgo racional burocrático del sistema educativo se apoya, o legitima su orden, sobre la base de formas patriarcales de ejercicio del poder. Si bien esta premisa general se cumpliría en las diversas instancias de la "carrera ascendente" (a cada una le corresponde un grado mayor de autoridad y poder, y en este sentido se aplicaría también a la dirección de las escuelas y siempre se accede por concurso), en el caso de la supervisión se profundiza por tratarse del cargo más político del escalafón, que transita "por fuera" del ámbito semicerrado de la escuela. Las mujeres en esos cargos deben ensayar otros modos...

Supervisión y ejercicio del poder: la necesidad de “estar ahî”...

Poner el cuerpo en un poder que no oculta su carácter político. Aún admitiendo el carácter político de su cargo, las supervisoras insisten en que son "docentes" y que su tarea compromete centralmente a las cuestiones pedagógicas de las escuelas. Como se reconocen explícitamente en su papel de funcionarias, parte del poder que construyen se apoya en la normativa que hace a la burocracia del Estado. En consecuencia, insisten por ejemplo en la implementación del Diseño Curricular, a través de la intervención en la formación, el asesoramiento y la articulación con 
Burocracia educativa, trabajo docente y género...

instancias de formación permanente. "Hay personas... no pondría a todos los hombres de un lado... pero como tendencia parecería que entre las mujeres hay más claridad en la función específica de la escuela... priorizan eso..." (Isabel).

La noción de "funcionariado" resulta generalmente incómoda ya que suele teñirse con la idea de la obsecuencia o de la falta de autonomía, rasgos desvalorizados por las definiciones "profesionalistas" de la docencia y por los/as profesionales convocados en forma intencional a los equipos técnicos. Sin embargo, si entendemos a la Política de Estado como "el conjunto predominante de iniciativas, respuestas y acciones que manifiesta una determinada modalidad de intervención del Estado en relación a una cuestión, caracterizada por una direccionalidad y orientación normativa contextualizada en un momento histórico" (Oszlak y O’Donnell, 1974, p. 56), el "funcionariado" asegura una cierta duración (aunque con adaptaciones a circunstancias cambiantes) y la adhesión a una cierta normativa conocida (leyes, decretos, resoluciones). Quienes se desempeñan en el ámbito del Estado y, en particular, en el sistema educativo son en este sentido los responsables de llevar adelante esas políticas de Estado.

Ahora bien, la tensión entre "ser funcionaria" y ser considerada como obsecuente está muy presente. Por ello señalan, con insistencia también, que es posible cambiar desde adentro y plantear disidencias cuando los proyectos aparecen como muy lejanos a las posibilidades de las escuelas. "Tomo lo que hay porque estoy en un sistema... lo discuto a todos... las cosas acá son así... parto del respeto hacia el sistema que me está pagando..." (Elisa). "El cargo de supervisor no es personal... vos sos un funcionario del estado... vos podés ser crítico, podés elevar otras opiniones pero sos un funcionario que tiene que dar cumplimiento a una serie de normativas... la autoridad pasa por que vos cumplas adecuadamente con estas directivas que se te dan..." (Isabel).

En ocasiones, son escuchadas; otras veces, desoídas. El curriculum es con frecuencia uno de los campos de tensión; tal vez el de mayor tensión funcionaria, ya que pone en juego al saber profesional docente (y su grado de pertinencia y solidez contextualizada a la vez que su actualización/desactualización) y a las relaciones de poder que dan existencia al sistema mismo. Pero aún en un marco de convicción sobre la necesariedad de la implementación y de valoración de la propuesta en desarrollo, 
la producción curricular implica algunas dimensiones que los equipos técnicos no llegan a anticipar, sobre todo si trabajan en forma aislada. Y las supervisoras saben que deben ejercer su poder en ese territorio... La autonomía en la relación funcionaria suele atravesar momentos de tensión no siempre bien manejados por las autoridades y no siempre comunicados en su sentido constructivo por parte de la supervisión.

A nosotros a veces lo que nos llamaba la atención era que había poca capacidad de escucha a lo que les decíamos... a veces se plantean algunas cuestiones con buenas intenciones pero con algún desconocimiento de lo que pasa en la realidad... A veces veíamos "esto va a ser difícil que ande"... lo planteábamos algunos... otros no, porque hay supervisores que a todo le dicen "amén" y está todo bien... todo fantástico siempre... No sé si lo hacían, pero es como que siempre están de acuerdo con el que está de turno... (Isabel)

Cuando una supervisora aparece como muy proclive al cumplimiento del diseño curricular se la descalifica con un "trae el diseño bajo el brazo"... Trabajar siguiendo los lineamientos curriculares o los proyectos oficiales en general no solamente no es aceptado por desacuerdos pedagógicos o políticoideológicos sino, con más frecuencia, porque representa un esfuerzo sentido como adicional a la tarea central. Para las supervisoras, deviene en "más malestar"... También saben que no es solamente la dimensión sustantiva del Diseño Curricular el motivo de disputa en las escuelas: también incide el problema de "hacer cumplir" la norma es parte de las dificultades de las direcciones que concentran la responsabilidad funcionaria mientras la vicedirección y la secretaría son "impunes". Siendo las direcciones sus interlocuciones más frecuentes, tampoco las supervisoras quieren meter más presión que la conveniente... Al igual que en el nivel de las escuelas, la conciencia de los límites predomina por sobre la necesidad de encarar problemas educativos (Anderson, 1991).

Devenir "funcionaria" parece implicar entonces mantener un delicado equilibrio entre el cumplir y hacer cumplir la norma que sostiene al sistema que les permitió el ascenso y, al mismo tiempo, lidiar contra las imágenes adversas que el mismo sistema evoca. En tanto "recién llegadas" (Bourdieu y Waquant, 1995, p. 56) las supervisoras, más desprovistas de capital de poder, parecen apoyarse en las estrategias de subversión, o la "herejía" - en una sociedad poco proclive a obedecer 
Burocracia educativa, trabajo docente y género...

las normas - de "sentirse" y "actuar" como funcionarias, usar las herramientas normativas y, a veces, lograr que se cumpla lo establecido y muchas veces se las ve como reglamentaristas o autoritarias... sobre todo suceden a un supervisor varón.

Ser modelo... Cuando era directora... yo llegaba muy temprano así que todos iban a cumplir horario... era la última en irme... conocía muy bien a los chicos... charlaba con las mamás, con los maestros... que estaba a disposición de todos los maestros... y que había cosas que decía "no va" y no va... Desde la supervisión es lo mismo... (Marta).

El modo que parece más convincente para legitimar a una supervisora que se concibe como funcionaria y trata a la vez de sostener profesional y críticamente los proyectos es, otra vez, como en el caso de las directoras, "lo hago yo primero"... y "dezspués exijo". Cuando me preguntaban cómo habia llegado a los resultados que tenía en la supervisión, yo decía "me pongo el mameluco" porque me pongo a trabajar a la par de los demás (Elisa). Ponerse "el mameluco", es decir, ropa propia del trabajo manual, significa otro sentido para poner el cuerpo: no se trata entonces de la vigilancia o la imposición, sino de plantearse llevar a cabo, a través del trabajo en su sentido más visible, una nueva versión de las políticas, institucional y pedagógica, trabajadas junto con autoridades y docentes de las escuelas: en algún sentido, el "mameluco" implica el intento de establecer una relación entre pares (Ball, 1994). El recorte del curriculum obviamente tiene que hacerlo Planeamiento pero lo que está pasando en la realidad de las escuelas...

Yo siempre digo... ¿¿Quién lleva a la práctica el curriculum? Los maestros... Hay que ponerse de acuerdo todos... Las modalidades y las metodologías nadie las toca... Las direcciones tienen que reunirse... no solamente a través de un listado... viendo cómo se enseña... en el 'cómo' nadie se mete... Sí nos metemos en la crítica... pero a veces el mismo maestro no sabe qué hacer... (Elisa).

La versión distrital e institucional de las políticas implica una suerte de "traducción", desde un lenguaje necesariamente general aunque en ocasiones formulado en textos excesivamente abiertos, a un mayor nivel de concreción... A la gente le hacen falta cosas concretas... como yo tenia la posibilidad de hacerlo, me lo agradecian... Armamos un esquema 
didáctico simplificado... la gente agradeció... (Isabel). Textos que interpelan a la creatividad y profesionalismo de equipos directivos y docentes pero que, con frecuencia, como hemos visto en el Apartado B, se encuentra con poca tradición y menos condiciones materiales para transformarse en prácticas escolares que vayan en el mismo sentido.

‘Cómo hacés'... Es una crítica real... Lo dicen todos... Pero quizás es que ellos no saben cómo hacerlo... ¿Cuál es nuestro rol? En la capacitación tal vez no se da lo que necesitan... no hay coherencia entre las necesidades y la capacitación... Aquello que critiquemos, tratemos de hacerlo nosotros... eso sería lo coherente... (Elisa)

Ponerse a trabajar "a la par" implica quebrar de algún modo la diferenciación que el imaginario tiende a profundizar como otredad jerárquica e insalvable. Es sabido el efecto de poder que provee el uso del lenguaje académico (a a veces cierta "jerga") que incrementa la distancia profesional; poder que, cuando se traduce en un ejemplo suele perder la potencia de la abstracción (y en este sentido se empobrece) pero que también puede perder la intensidad propia de la intriga: el "¿qué habrán querido decir?" puede provocar un rechazo explícito en algunas estructuras de participación mientras que en otras abona al mantenimiento de la diferencia jerárquica no colegial. Si bien parecería que la "modelización" es la modalidad que más frecuentemente utilizan las mujeres/femeninas en la construcción del orden que legitime su liderazgo, las rasgos particulares que esta modalidad toma en la supervisión se vinculan con el carácter "lejano y amenazante" del cargo: ser modelo entonces parece mucho más inusual, mucho más disruptivo; a veces, hasta desorienta... pero, a la larga, parece favorecer a la autoridad femenina.

Conducir "con el mameluco" entonces tiene algunos riesgos que las supervisoras tienen que correr... Por una parte, la noción tópica del poder arriba-abajo en el sistema educativo parece combinarse - y reforzar - en cierta medida la división concepción-ejecución que las teorías curriculares más progresistas intentan desterrar sosteniendo que existen diferentes niveles de especificación curricular y que en las aulas se produce el tercer nivel profesional; el "mameluco" puede transformarse en un proceso simbólico de "bajar" una producción "elevada". Verse más en la proximidad del "codo a codo" también hace correr el riesgo de "confusión" que la cercanía afectiva puede producir en el terreno del cumplir y hacer cumplir... 
¿Cómo lo logré? Con el trabajo continuo, con venir, con hacerme cargo, con estar desde las 8 hasta las 16. Cumplir, trabajar, cuando hay un problema me esfuerzo, doy la cara, me juego... y fui construyendo una red de lealtades que dice 'esta tipa se mueve'... Pero no concedo favores... Esto juega en contra... yo digo 'hay que trabajar'... eso me costó... Mi marido me dice 'dejalos'... pero va contra mis principios... si yo tengo un cargo y lo acepté... Yo trabajo y ellos tiene que trabajar... (Teresa)

Poner el cuerpo de maneras ostensibles... "Me esfuerzo, doy la cara, me juego"... parece confundir a veces a la base ya que representa el intento de construcción de una autoridad profesional no violenta versus la organización burocrática tradicional.

El involucrarse sosteniendo un proyecto pedagógico implica mantener a la infancia en el horizonte; una infancia que, a veces, queda demasiado lejos de la vida cotidiana adulta (docente y familiar) de la comunidad educativa. Y mucho más lejos de la supervisión.

Es como que nos quedamos en el medio discutiendo los adultos y como que los chicos no entran en la discusión... Y en ese todo también incluyo a los padres que demandan mejores resultados de aprendizaje... cómo trabajo con esa comunidad... son muchas las cosas en las que tenés que meterte... (Elisa)

La dificultad de "ser modelo" entonces, una y otra vez, encuentra tensiones vinculadas con los modos más tradicionales de ejercicio de la supervisión y con las definiciones estructurales del sistema educativo. Es posible que este recurso consista en una nueva forma de "herejía" de las recién llegadas... O bien, para decirlo en otras palabras, el modo de construir poder entre quienes no lo tienen "desde siempre". Sin embargo, la investigación las encuentra en esa posición de relativamente "nuevas" y toda otra anticipación es solamente una hipótesis... si los contenidos no violentos se sostienen en el tiempo, es posible que la construcción modelizada del orden llegue a ser el fundamento de relaciones profesionales basadas en la colegialidad... Pero, al borde de la jubilación, las supervisoras difieren en el grado de optimismo con el que ven a su trabajo y las perspectivas de futuro... Me parece que falta compromiso... en algunas docentes... Me voy desilusionada del sistema... A pesar de los esfuerzos, las propuestas, la gente bajó la guardia en el sentido del compromiso... (Isabel).

Seguir siendo maestra... y saber. El papel funcionario parece construir su poder con el mismo sesgo "femenino" que legitima la tarea de 
las directoras: constituirse en un modelo de trabajo... Sustantivamente, las estrategias de legitimación de esa modalidad parecen tener, nuevamente también, una incidencia importante del componente pedagógico de la tarea: enseñar, cuidar y también, acompañar...

Concebirse como "una maestra" implica desplegar actividades propias de la tarea del aula: planificar (la tarea de la supervisión en este caso), trabajar sobre "contenidos" (tanto sustantivos de las diferentes áreas curriculares cuando se trata de la actualización teórica y didáctica como las cuestiones de conducción organizacional y comunitaria), argumentar y pedir argumentaciones, estimular a que otros y otras aprendan y evaluar el proceso en forma constante... una forma poco frecuente de ejercicio del papel de la supervisión, más centrada en la "enseñanza a otros y otras" en algunas, más centrada en el "propio saber" en otras, pero siempre relevante para nuestras entrevistadas.

Cierto respeto que se ha ganado durante cierto tiempo... además fui 20 años maestra de grado... tuve experiencia y eso es importante qorque te permite tener otra visión... (Isabel)

Es un rol similar al del maestro... pero para mí siempre estás enseñando... Como maestro preparás tus prácticas... como director preparás tus prácticas... bueno, también como supervisor preparás tus prácticas... desde otro lugar pero no podés no planificar, no tener una fundamentación téorica... no podés no pensar cómo asesorarías, cómo llevarías a cabo esta idea que tenés... Sigue siendo un trabajo docente, no es que estás en un pedestal... tenés que seguir trabajando... (Elisa)

Sostener una posición enseñante parece, en primer lugar, vincularse con el registro de la necesidad y de la capacidad de seguir aprendiendo... Y seguir estudiando, ya no con la presión del ascenso: las credenciales educativas habilitaron el acceso al concurso pero no dejan de tener presencia en el proyecto profesional de las supervisoras; el deseo de saber más, de mantenerse actualizadas, de tener más respuestas vinculadas con el "cómo hacer": 'Nos ponemos en grupo, uno que asuma el rol'... Trabajar sobre ellos mismos... ese tipo de trabajo lo aprendi... y voy creando sobre cosas que aprendi... Cuando hicimos esa capacitación de supervisión aprendimos cómo construir el PEI con tanta gente disímil... y me costó... pero aprendí (Elisa).

Los contenidos de ese papel enseñante se vinculan con las necesidades de los/as interlocutores/as más frecuentes de la supervisión: los 
Burocracia educativa, trabajo docente y género...

equipos directivos. Además de los enfoques nuevos en las diferentes disciplinas curriculares que requieren de la actualización profesional continua, también el papel enseñante de la supervisión se juega en las cuestiones institucionales.

\begin{abstract}
Ahí tuvimos varias etapas... primero era como que cada uno hacía el PEI como le parecía... luego hubo lineamientos... en una época se llamó Proyecto Institucional Participativo... En la época de la Ley Federal hubo mucha capacitación... siempre se trató de aplicarlo... una escuela hacía algo que no tenía que ver con la otra... hubo que barajar de nuevo... yo me manejaba mucho con el libro del PEI, uno básico... Decidimos hacer reuniones... primero con el equipo de supervisoras curriculares... les pareció bien... yo me llevé bien con la gente del equipo... aunque reformaría esa estructura... pero siempre me vienen a consultar... con el equipo del distrito... hicimos una serie de indicaciones concretas... "lo que no puede faltar en el PEI" dimos copias... mejoró bastante... Igual hay gente que pone cualquier cosa... (Isabel)
\end{abstract}

Así, aparecen como "contenido" la organización del tiempo de la escuela, la planificación y conducción del proyecto educativo institucional, los modos más apropiados para realizar el asesoramiento y el seguimiento... No saben cómo organizar, cómo coordinar, qué cosas saber... la distribución de tareas, el espacio físico... no saben... están trabajado en capacitación directiva pero que hay que enseñarles 'esto hay que hacerlo asi'... (Elisa). La propia experiencia previa en la dirección puede resultar una fuente para esos saberes, pero también la formación permanente, formal y autodirigida...

Lo primero que sale es que no tienen tiempo... Pero les tenés que enseñar cómo hacerlo... si no trabajás en los tiempos sonaste... es una excusa, pero no podés decirles así... no podemos organizar un equipo de trabajo si no hay tiempos comunes... cómo voy a llegar a la formulación del proyecto educativo... no es que nos tenemos que reunir todos, sino con mini grupos... Si querés hacer una plenaria, perfecto... Una vez que está organizado, se buscan los tiempos por necesidad... No pueden trabajar por ciclo si no se reúnen... El sentir el gusto de reunirse... (Marta)

El saber de la experiencia como condensado de conocimientos teóricos sistemáticos y retazos de conclusiones fácticas. Si bien la ciencia moderna se encargó sistemáticamente de reducir el valor de la experiencia a un estadío inicial y de alguna manera sospechoso en la pro- 
ducción de conocimiento (Larrosa, 2003), parecería que entre docentes goza de una fuerte valoración que legitima las intervenciones de la supervisión: Bueno, la cuestión es que fui construyendo la capacitación, no solamente la capacitación desde la Escuela de Capacitación sino al Supervisor como capacitador (Elisa).

Pero esta relación tiene también otros "contenidos". Teresa sostiene que siempre es posible mejorar y aprender... pero reconoce que es dificultoso... y trata de animar a quienes encuentra con intereses sustantivos: Hay algunos nuevos... trato de que no se cansen... la gente tiene dificultades con su parte emotiva... aunque también trato de enseñarles a los directores a que salgan adelante solos... Salir adelante, independizarse de la protección y del aval es también una cuestión que las direcciones necesitan "saber"... aunque, en un sistema piramidal, se actualiza una y otra vez la necesidad de trabajar la autonomía dentro de los márgenes posibles y las diferentes situaciones que el sistema plantea. Siguiendo la línea de análisis de Stephen Ball (1994, p. 84), parecería que la coexistencia de "órdenes" en las estructuras de poder (en cierta medida "burocrático", en cierta medida "autogestionado" y en cierta medida "profesional") genera un pasaje constante entre posiciones de sujeción o dependencia y otras en que quienes tienen la "responsabilidad última" deben asumirla y hacerse cargo de sus consecuencias... Volveremos sobre esta cuestión más adelante.

La intención enseñante tiene además fuertes obstáculos si se encuentra sin reconocimiento del otro lado de la relación laboral. Para transformarse en "maestras de directoras/es" parece central que se les reconozca un saber distinto y más amplio... aunque entre las supervisoras no parece unívoca la visión respecto del modo material de ejercer su función: ¿Hay que ir a las aulas o hay que formar a los equipos directivos para que vayan a las aulas?.

A veces tenés que ir porque lo que las direcciones te dicen no es suficiente... (Teresa).

Yo creo que trabajaba bien en las visitas a las escuelas en las conversaciones con el equipo directivo... siempre que estuviera... me servía como para tener una impresión acabada de lo que pasaba en la escuela... me sentía cómoda... lo mismo en las reuniones con directores... informativas o de trabajo... hubo muchas reuniones por la hoja de concepto... me sentía muy cómoda trabajando y asesorando... me lo reconocían... me veían con seguridad... No quiero ser pedante, pero como que estaba un escalón más arriba en los conocimientos... (Isabel) 
El grado de compromiso o "intromisión" en la práctica de los equipos directivos en una labor poco formalizada - no están reglamentadas las formas en que la supervisión debe trabajar en las escuelas -, con fuertes antecedentes de coerción y control y en que las normas tienen un escaso peso específico, requiere una combinación de formas de legitimación que, como veremos más adelante, suelen requerir una combinación de prácticas "innovadoras" y prácticas tradicionales de las que parece imposible zafar del todo...

El acompañamiento personal... si lo piden y lo permiten... Teresa lamenta que cerca de la mitad de su tiempo me la paso tratando de apagar incendios... Desde su perspectiva, los/as directores/as sienten que están solos/as, que las familias no solo no acompañan sino que son parte del problema, que no tienen recursos en escuelas con excesiva cantidad de chicos/as... Paso el dia tratando de sofocar angustias, ansiedades... El sostén cotidiano... No dejarlos solos... es importante, cuando llaman al distrito... es importante que no los dejes... no 'vamos a ver en un semana' sino en el momento... y si se le ponene muy dificiles a ellos... (Isabel).

Desde la perspectiva de Teresa, la sensibilidad femenina, que tiende a atender con mayor dedicación a los sentimientos y al dolor, le permite hacer una conexión emocional con algunas directoras que resulta positiva para apoyarlas. Pero la parte masculina mía, de la organización y poder decir con claridad 'no... tenés que entrar en horario'... sirve para poner limites... pero al mismo tiempo contemplo los casos particulares... Los "casos particulares" integran el universo de las decisiones que se toman con "cuidado", de "correr el límite" cuando cabe según los antecedentes que el vínculo personal permite conocer, cuidado de escuchar un pedido de auxilio que requiere más que una visita puntual y también de darse cuenta de qué límites son infranqueables:

Vos sentís a veces cuando vas a una escuela que piensan 'cuando se irá esta mujer'... Aca hay un director que es excelente... de una escuela grande... pero él... no sé si problema de machismo... estuve como siete años... nunca pude pasar la pared... la vez que se acercó más fue cuando murió mi marido y vino a saludarme... no se dejaba asesorar... es farmacéutico... tal vez eso... siempre parece lavado y planchado... respeto sin una conexión... (Isabel)

Trabajar mucho y ¿con cuidado? Las resistencias... tenés que saber que va a haber... y vas allanando el camino... yo le daba un tiempo de sensibilidad a la propuesta... mayor que la propuesta misma... La resistencia es 
una constante que apunta al desgaste de la supervisión... constante hasta que instalé la propuesta... si la instalé es porque el otro estaba consustanciado por el proyecto... (Elisa). Las supervisoras conocen bien la necesidad de sostener un proyecto con mucho trabajo pero también la dimensión política que implica; cuando logran manejarla, encaminan también sus proyectos pedagógicos de distrito escolar.

Se dice con frecuencia que un/a gobernante o un/a lider/es deben tener "cintura política". En su acepción más positiva se entiende que si tienen "cintura política" conducirán sus proyectos tendiendo a anticipar o, mejor, evitar episodios de oposición y de conflicto, costosos desde el punto de vista personal e institucional. En su acepción más negativa ("maquiavélica", según el sentido corriente de la obra de Maquiavelo ${ }^{15}$ ), la "cintura política" podría entenderse como el cálculo externo, una "táctica" dentro de una estrategia que no siempre conveniente a todos y todas... En esta acepción, integran la "cintura política" el contar con contactos o información adicional a través de "espías", usar voceros que siembren las ideas entre la base en forma anticipada, guardar silencio en una forma de solidaridad corporativa, mantenerse inmutable frente a una denuncia, un desborde o un insulto, hablar "a solas" con jefes/as o subordinados/as para convencer o para amenazar de manera implícita o explícita etc... No parecen ser las tácticas que las supervisoras emplean en su búsqueda de legitimidad... aunque las supervisoras - que conocen algunas de esas prácticas pero, según sus testimonios, no las emplean con frecuencia - entienden la necesidad de identificar y anticipar las claves para llevar adelante un proyecto "funcionario".

Por ejemplo, usar tiempo en la "sensibilización", es decir, en la presentación de las características y fundamentos de la propuesta, y aguardar el momento apropiado: saben que, aunque es central mantener la tensión, a veces es mejor no acelerar demasiado los tiempos. También saben que es importante elegir las circunstancias y formatos en los que esa presentación se realiza (a veces en público, a veces a solas...) y que es necesario convocar a todos los actores que deben saber y participar de un proyecto... Con consideración de personas, instituciones y también de los propios proyectos políticos: ocuparse de allanar el camino avisando... o tratando de evitar resistencias politicas... con un proyecto pedagógico (Elisa). Anticiparse antes de que el conflicto suceda... Es un trabajo de sensibilización... para cualquier proyecto... Hay 
Burocracia educativa, trabajo docente y género...

que entenderlo, no lo podés imponer... cada vez tenés que empezar como si fuera de cero. Una tarea que no tiene fin... No terminé nunca porque los chicos siempre se renuevan y nos están esperando... (Elisa).

La gradación parece deslizarse desde la "obediencia forzada" a la investidura para pasar, posteriormente, un cierto reconocimiento a la "persona” que la porta, para volver otra vez a la investidura resignificada como liderazgo pedagógico... Ese proceso parece darse en todos los casos, pero dada la escasa tradición de presencia pedagógica en la supervisión parece particularmente costoso. Tenés que negociar... con el gremio, con todos... pero siempre desde una fundamentación... te respetás a vos misma... Es irrenunciable... el enseñar y el aprender nosotros mismos... es irrenunciable... (Elisa).

También el Ministro o Ministra de Educación, el director o directora de área suelen ser objeto de "evaluaciones" desde la base... Parecería también que ese cuidado se vincula con manejar con cierta firmeza la compleja relación con las autoridades. Las supervisoras enfrentan el desafío de hacer cumplir una norma (el curriculum por ejemplo) apoyadas en su saber y en su sentido de la oportunidad, es decir, en cierta medida, ponen en juego su prestigio acumulado; "bajar" los proyectos de la gestión de modo automático puede descalificarlas frente a la base... También entonces deben cuidar su prestigio... Y también las características personales... que seas más o menos manejables por las situaciones... y si tenés las cosas claras sabés cómo manejar situaciones... Asi vas construyendo tu autoridad... (Isabel). Con una autoridad construida a través del trabajo, una supervisora también llega a contar con un "capital" de poder para poner en juego.

El otro capital con el que cuenta una mujer supervisora, al igual que las mujeres en general, es el cuidado en el trato. No se trata de una naturaleza femenina más "amable"; se trata de una forma de pedir a otro $\mathrm{u}$ otra que haga algo incluido en sus funciones pero sin suponer que "va de suyo" que el otro u otra debe obedecer.

Hay gente que gritonea o manda... yo pido 'por favor, me podés hacer esto cuando termines'... también me agarré mis grandes broncas... me ven la cara... Hay momentos en que tenés que poner el limite... también con padres que te quieren atropellar... tenés que estar segura de lo que estás diciendo... (Teresa)

Sin embargo, Teresa no ha tenido experiencias negativas por su condición femenina. Solo registra un esfuerzo mayor. Un esfuerzo de 
cuidado, de tacto... que no siempre sin embargo redunda en los resultados esperados; siempre puede haber sorpresas, situaciones insospechadas que aún que desafían aún a los recursos más probados...

Un tema interesantísimo que es cómo trabajar con las agresiones, cómo trabajar el grupo frente a las agresiones... Si bien hacía los talleres, y yo estaba muy contenta, en algún momento se producía alguna cosa que algún director agredía o decía algo porque no quería saber nada con todo esto. Entonces, en el grupo de trabajo que teníamos con ella, me daba herramientas como para trabajar sobre eso. Cuando llegué acá como supervisora, empecé con eso pero era un rechazo total porque ellos querían a la otra supervisora que yo 'la había desplazado'... aunque no me lo decían a mí. Tuve que trabajar eso. (Elisa)

Una forma menos reconocida o nombrada como "cintura política”... vinculada con el cuidado antes que con la manipulación o la influencia.

\section{Conclusiones}

El concepto de "carrera" no es adecuado para pensar al desarrollo profesional docente, ya que conserva un sesgo "liberal" masculino y tampoco parece apropiado persistir en una organización institucional en la cual la única manera desarrollar una profesionalidad sea "salir del aula" y "dejar de enseñar". Desde la perspectiva de la gestión, la tarea directiva carga con contenidos administrativos y de gestión de recursos que también parecen alejados de la especificidad pedagógica del trabajo.

En el marco de conflictividad social actual, en el cual la escuela conserva un lugar entre las instituciones de referencia de la comunidad, se agregan expectativas que en ocasiones resultan desmedidas para las posibilidades, recursos y, sobre todo, especificidad de la tarea escolar. La configuración que estos antecedentes genera implica una cotidianeidad signada por el "ir detrás de los acontecimientos" y que "otro/s u otra/s coloquen la agenda". La conducción escolar solo responde a urgencias o presiones; la "gestión" como respuesta a interrogantes puestos desde "afuera" abona tanto a la tentación de "esconderse detrás de los papeles" como a la de imponer, autoritariamente otra vez, las reglas del juego de modo patriarcal. En esta dinámica, entendemos que 
Burocracia educativa, trabajo docente y género...

las prácticas vigentes configuran una importante alienación de los saberes pedagógicos, ya que las urgencias, las presiones o las emergencias tienden a reducir la incidencia de la supervisión de la enseñanza y el cuidado como prioridad de la propia tarea.

Es evidente que la presencia de mujeres en la supervisión en forma proporcional a la base docente sería "justo" en el sentido redistributivo de la justicia de género (Fraser, 1995, p. 34), aunque serían necesarios algunos cambios organizacionales para que, en pos de una justicia de reconocimiento, también puedan construirse formas del poder en el sistema educativo más apropiadas a los modos culturales femeninos que, en cierta medida, podrían incidir también en la construcción de mayor autonomía en el trabajo de los equipos directivos y docentes. Probablemente será necesario luchar por una modificación en los estatutos de la estructura de la "carrera" y encontrar nuevas alternativas de desarrollo profesional para las mujeres en la docencia. Sostenemos entonces, tanto teórica como empíricamente, que la alianza con la política y la lucha en el terreno del estado siguen siendo una apuesta clave en la transformación feminista de las relaciones de poder en las instituciones, al menos en las educativas.

\section{Recebido em maio de 2007 e aprovado em junho de 2007.}

\section{Notas}

1. El Distrito Escolar es una subdivisión geográfica de la administración del sistema educativo que, ene general, abarca entre 18 y 25 escuelas y tiene un/a supervisor/a escolar y un/a supervisor/a adjunta a cargo, por concurso y como carrera ascendente (es decir no se retorna a un cargo inferior al cabo de un periodo sino que es vigente hasta la jubilación).

2. Seguiremos en estos puntos, además de nuestros propios trabajos anteriores, los sugerentes aunque controversiales aportes de la ética del cuidado desarrollada por Nel Noddings $(1984,2002)$ y por los colectivos europeos de las feministas de la diferencia sexual agrupados con el nombre de "Sofías".

3. La cuestión de la "identidad" es un problema ampliamente abordado en las ciencias sociales. El concepto de "identidad" (docente en este caso) que adoptamos se nutre de la tradición postestructuralista y en particular de los desarrollos de Judith Butler (1990, 2001).

4. Decimos "contradictorio" porque, en algunos casos, los mandatos sociales vinculados con uno de los órdenes de poder (el de clase por ejemplo) pueden entrar en colisión con otro emanado de otro orden (por ejemplo, la democracia liberal en que todas las personas tienen los mismos derechos).

5. A partir de la reconstrucción de los procesos subjetivos de transformación que hacen que una persona se sienta y se conceptualice a sí misma como "maestra" o "maestro", es posible 
también discutir que esa autodefinición se produzca necesariamente en el momento de recibir la acreditación profesional.

6. La noción de "experiencia" tiene una tradición importante tanto en los Estudios de Género - Joan Scott, por ejemplo (1990 como, más recientemente, en la pedagogía en los trabajos de Jorge Larrosa).

7. Si bien el concepto de "sistema de sexo-género" se encuentra en construcción y revisión permanentes, adoptamos como marco de interpretación los postulados de Joan Scott y su profundización junto con Conway y Bourque (1998).

8. Por ejemplo, investigadoras como Silvia Yannoulas (1996), Guacira Lopes Louro (1997) o Marcia Ondina Vieira Ferreira (2004).

9. Se trata entonces de un proceso en que no existe una imposición total sino, retomando el pensamiento gramsciano (Gramsci, 1975), más bien una dinámica de coerción y consenso en tensión permanente, que produce configuraciones particulares y a la vez dislocaciones producto de la lucha de entre sujetos colectivos o de las contradicciones entre diferentes esferas de la vida social (Laclau y Mouffe, 1987).

10. Solo recientemente ( $y$ no en todo el país sino en algunas jurisdicciones) existe una formación particularizada para estas funciones.

11. En el próximo apartado, revisaremos en profundidad la tradición prediminante en las Ciencias Humanas y Sociales que entiende a la construcción de los Estados nacionales como el "monopolio del uso de la fuerza" y analizaremos también la producción de Hannah Arendt (1997), que propone una alternativa no violenta de conceptualización del poder.

12. Entendemos, con Max Weber, que la burocracia es la forma de dominación más típicamente moderna, sosteniendo al mismo tiempo que el aparato del gobierno del Estado es un espacio de lucha y contradicciones antes que un todo homogéneo dirigido a sostener la dominación sobre la sociedad civil. En este sentido, nos apoyamos en la obra de Michel Foucault y, ya citados, en los desarrollos que Ernesto Laclau y Chantal Mouffe (1987) realizaron sobre la obra de Antonio Gramsci.

13. Que remite, nuevamente, a la construcción de los Estados nacionales como monopolio del "uso de la fuerza".

14. Las nociones de "igualdad" y de "igualdad compleja" se retoman de los desarrollos de María Isabel Santa Cruz (1992).

15. Es interesante subrayar que en las lecturas que Gramsci formula sobre la obra de Maquiavelo, el sentido "negativo" (es decir, entendiendo que El Príncipe es un manual para tiranos) resulta discutido: para Gramsci, lo que hace Maquiavelo es inaugurar la "teoría política" y, en ese sentido, analizarla actividad autónoma, o sea, como actividad basada en leyes y principios distintos de los de la religión y la moral. Por ello servirá tanto a quienes sostengan una voluntad de manipulación como a quienes deben conocer las reglas de la política para evitar ser manipulados/as Cf. Gramsci (1975).

\section{Referencias bibliográficas}

\section{ANDERSON, G. Cognitive politics of principals and teachers: ideological control in an elementary school. In: BLASE, J. (Ed.). The politics of life in schools. Newbury Park: Sage, 1991.}

Educ. Soc., Campinas, vol. 28, n. 99, p. 400-425, maio/ago. 2007 
Burocracia educativa, trabajo docente y género...

ARENDT, H. ¿Qué es la política? Barcelona: Paidós, 1997. (1. ed. 1950)

BALL, S. La micropolitica de la escuela: hacia una teoría de la organización escolar. Barcelona: Paidós, 1994.

BATALLÁN, G. El poder y la autoridad en la escuela: la conflictividad de las relaciones escolares desde la perspectiva de los docentes de infancia. Revista Mexicana de Investigación Educativa, México, v. 19, n. 8, set./dic. 2003.

BOURDIEU, P.; WAQCUANT, L. Respuestas: por una antropología reflexiva. México: Grijalbo, 1995.

BUTLER, J. Gender trouble: feminism and the subversion of identity. London: Routledge, 1990.

BUTLER, J. Cuerpos que importan. Madrid: Paidós, 2001.

CONWAY, J.K.; BOURQUE, S.C.; SCOTT, J.W. El concepto de género. In: Navarro, M.; Stimpson, C.R. (Comp.). ¿Qué son los estudios de mujeres? Buenos Aires: Fondo de Cultura Económica, 1998.

CORTINA, R.; SAN ROMÁN, S. Women and teaching: global perspectives on the feminization of a profession. New York: Palgrave MacMillan, 2006.

EPSTEIN, I. Gramática do poder. São Paulo: Ática, 1993.

FELDFEBER, M.; OLIVEIRA, D.A. Políticas educativas y trabajo docente: nuevas regulaciones, ¿nuevos sujetos? Buenos Aires: noveduc, 2006.

FERREIRA, M.O.V. Mulheres e homens em sindicato docente: um estudo de caso. Cadernos de Pesquisa, São Paulo, v. 34, n. 122, 2004.

FRASER, N. From redistribution to recognition?: the dilemmas of justice in a 'postsocialist' age. New Left Review, London, n. 212, jul./ aug. 1995.

GRAMSCI, A. Notas sobre Maquiavelo. México, DF: J.P. editor, 1975.

HARGREAVES, A. Profesorado, cultura y posmodernidad. Madrid: Morata, 1996. 
LACLAU, E.; MOUFFE, C. Hegemonía y estrategia socialista. Barcelona: Ariel, 1987.

LARROSA, J. Experiencia y pasión y sobre lectura, experiencia y formación. In: LARROSA, J. Entre las lenguas: lenguaje y educación después de Babel. Barcelona: Alertes, 2003.

LOURO, G.L. Gênero, sexualidade e educação. Petrópolis: Vozes, 1997.

MORGADE, G. Mujeres en la educación: género y docencia en la Argentina (1870-1930). Buenos Aires: Miño y Dávila, 1997.

NODDINGS, N. Caring, a feminine approach to ethics \& moral education. Berkeley: University of California, 1984.

NODDINGS, N. The challenge to care in schools: an alternative approach to education. New York: Teachers College, 1992.

NODDINGS, N. Starting at home: caring and social policy. Berkeley: University of California, 2002.

SANTA CRUZ, M. Sobre el concepto de igualdad. Isegoría, Barcelona, n. 6, 1992.

SCOTT, J. El género, una categoría útil para el análisis histórico. In: Amelang, J.; NASH, M. (Ed.). Historia y género: las mujeres en la Europa moderna y contemporánea. Valencia: Alfons el Magnanim, 1990.

YANNOULAS, S. Enseñar ¿una profesión de mujeres? Buenos Aires: Kapelusz, 1996. 